To Hern, by contrast, the personal is everything. What a City Is For is predominantly an examination of the impact of planning policy on local communities and individuals, particularly in relation to gentrification. There are inevitable echoes of Jacobs's thinking, such as her concept of 'unslumming' - seeing and encouraging the inherent value in poorer neighbourhoods, rather than sweeping them away. But Hern reveals how residents' trust in any official intervention has deteriorated. He starts in Portland, Oregon, where discriminatory planning legislation has effectively made a ghetto of Albina, a black neighbourhood. When the local authority tried to upgrade the area, residents resisted, convinced of impending displacement. Activists told Hern that they knew black residents were doomed as soon as they saw the community gardens and bicycle lanes.

Hern is at pains to check his privilege as a white man speaking on predominantly black issues. He writes "cautiously and hopefully with humility", endorses conflicting arguments and seems unwilling to offer clarifications. The result is confusing: an apologetic polemic. Hern even wonders whether communities are actually merely refuges for "misogynist oppression, violence, and misery", leaving the reader to wonder what is being defended other than the process of community defence. In essence, this is a book about power relations, but not in the dualistic manner of Jacobs versus Moses. Rather, it's a more fundamental rejection of anyone's right to set standards of what a good community or city should be. A truly democratic commons would obviate the concept of ownership, Hern argues, because all land was stolen from colonized peoples. Cities, he feels, need to "disown" themselves.

The great US urbanist Daniel Burnham once said: "Make no little plans." Sixty years later, Jacobs decried the arrogance of such grand modernist thinking. A further 60, and Hern is opposed to the very concept of conscious planning. Jacobs was hugely influential in democratizing the planning process, and in supporting socio-economic and cultural diversity by advocating variety in architecture and vitality in shared spaces. But she saw urban diversity as fluid. Hern treats diversity as a value in its own right, and seems compelled to endorse social fragmentation in the name of increasing socioeconomic and ethnic diversity, to the point of urban liquidation. I don't think Jacobs would have approved.

Austin Williams is associate professor of architecture at Xian Jiaotong-Liverpool University in Suzhou, China, and the author of the forthcoming China's Urban Revolution.

e-mail:futurecitiesproject@gmail.com

\section{Books in brief}

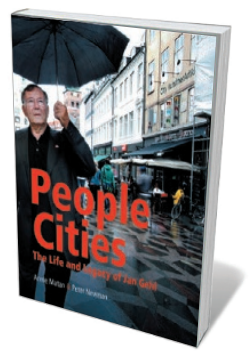

People Cities: The Life and Legacy of Jan Gehl

Annie Matan and Peter Newman ISLAND (2016)

For half a century, Danish architect and writer Jan Gehl has been enacting a revolution in people-centred urban design. Like Jane Jacobs (see page 614), Gehl rejects the sterile functionalism of modernism, instead methodically analysing human behaviour in shared spaces — the "life between buildings" — to isolate criteria for holistic planning. This in-depth, illustrated biography by Annie Matan and Peter Newman follows the evolution of Gehl's theories as he 'reconquers' cities from London to Sydney with pedestrianized streets, bike lanes, enriched 'edge environments' and more.

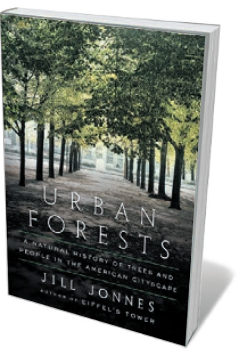

\section{Urban Forests}

Jill Jonnes VIKING (2016)

The deforestation that ran rampant in the United States through the nineteenth century spurred a band of doughty dendrologists and politicians to forest the cities. Jill Jonnes' stimulating history chronicles their collective story, from William Hamilton (who reintroduced Ginkgo biloba to North America millennia after it was glaciated out) to the many scientists struggling to control blights and beetles. Today, Jonnes shows, despite trees' measurable benefits for human well-being and microclimate regulation, urban forestation remains at risk from short-sighted redevelopment.

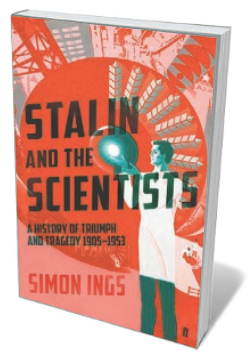

\section{Stalin and the Scientists}

Simon Ings FABER \& FABER (2016)

When Joseph Stalin died in 1953 after ruling the Soviet Union for more than 20 years, the nation's science was "the glory and the laughing stock of the intellectual world", notes Simon Ings. His monumental chronicle follows hordes of brilliant scientific chancers who welded their talents to the fledgling union, only for many to 'disappear' into the gulags, or mentally atrophy under the leaden hand of bureaucracy. Ings ably tweezers the discoveries and disasters out of this political train-wreck, from the triumphs of psychologist Lev Vygotsky to the pseudoscience of agrobiologist Trofim Lysenko.

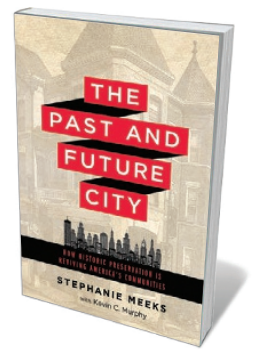

The Past and Future City: How Historic Preservation is Reviving America's Communities

Stephanie Meeks with Kevin C. Murphy ISLAND (2016)

The US suburb may be on the wane, as recognition grows of how unsustainable long car commutes really are. So suggests Stephanie Meeks in this punchy study of the "great inversion" - the flow of younger people into historic city centres. Meeks, who helms the US National Trust for Historic Preservation, presents metrics from its research arm and copious case studies to argue that renovation is greener and older urban districts socio-economically superior - but warns against the diversity-crushing tendencies of gentrification.

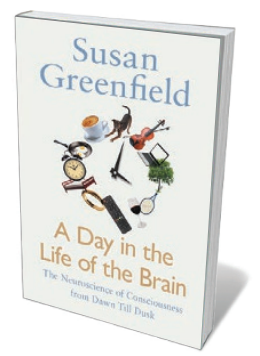

A Day in the Life of the Brain

Susan Greenfield ALLEN LANE (2016)

As we traipse through our day, what is happening inside our brainpans? Neuroscientist Susan Greenfield investigates consciousness from waking to sleeping, drawing on her own research into neuronal assemblies - evanescent coalitions of neurons that ripple across the brain — and that of myriad other scientists, from Antonio Damasio to Rodolfo Llinás. An illuminating, engrossing journey into (and beyond) the biology of time, the synergism of walking and cognition, and the phylogeny of dreams. Barbara Kiser 